\title{
Paisagem e natureza na arte contemporânea: ressignificação do espaço e experiência da obra
}

\author{
Ana Marcela França \\ Pós-doutoranda do Conselho Nacional de Investigações Científicas e Técnicas (CONICET), Argentina, e CEAR — Universidade Nacional \\ de Quilmes.
}

Contato: anamarcelaf@hotmail.com

\section{RESUMO}

O presente artigo se propóe a discutir sobre as instalaçóes realizadas nos anos 1970 até a atualidade, que dialogam diretamente com a paisagem "natural", estendendo a significação do objeto artístico à reconfiguração espacial. Em especial, serão discutidos trabalhos que atuam no espaço biofísico, em que elementos da geografia do lugar se tornam dispositivos da manifestação artística. Será visto que essas atuaçôes transformam a paisagem e a própria noção de obra de arte, criando tensóes naquilo que compreendemos como natureza e cultura.

Palavras-chave: Paisagem, Arte, Espacialidade

\section{ABSTRACT}

This paper aims to discuss the installations made in the 1970s to the present day, which dialogue directly with the "natural" landscape, extending the significance of the artistic object to the reconfiguration of the space. In particular, works that have action in the biophysical space will be discussed, in which elements of the environment become devices of artistic manifestation. It will be seen that these performances transform the landscape and the notion of a work of art, creating tensions in what we understand as nature and culture.

Keywords: Landscape, Art, Spatiality 


\section{Introduçáo}

O desdobramento da obra de arte no espaço da realidade foi relevante em diversos trabalhos da vanguarda moderna e contemporânea. $\mathrm{O}$ entendimento do campo de significados sugerido por esses trabalhos passa a ser deflagrado na externalidade do mundo, onde a relação distanciada entre espectador e obra é substituída pela inter-relação entre obra, espectador e vida. $\mathrm{O}$ espaço da obra se torna um desdobramento no espaço da vida, em que a realização da arte seria a sua atuação no ambiente da realidade tangível.

O presente artigo se propóe a discutir sobre instalaçôes que dialogam diretamente com a paisagem "natural”, estendendo a significação do objeto artístico à reconfiguração espacial. Em especial, serão discutidas obras que atuam no espaço biofísico, em que os elementos da geografia do lugar se tornam parte da manifestação artística. São espaços abertos ou pertencentes a parques e jardins, mas que interagem diretamente com os elementos naturais. Será visto que essas atuaçôes transformam a paisagem e a própria noção de obra de arte, criando tensôes naquilo que compreendemos como natureza e cultura.

\section{I.}

A compreensão do ambiente natural por parte dos artistas modificou-se ao longo do processo histórico, tomando diversos aspectos nesse percurso. Por vezes a paisagem representou a experiência subjetiva do individuo no mundo, como por exemplo no romantismo alemáo, por vezes foi motivo da pesquisa pictórica, como é o caso das pinturas de Cézanne. Alguns estudiosos consideram as representaçóes de paisagem como um reflexo do meio sociocultural em que o artista vive, onde se teria nela a imagem dos valores do indivíduo integrado a uma dada sociedade. Para a filósofa Anne Cauquelin, em seu livro $A$ invenção da paisagem, a paisagem seria vista como um "enunciado cultural", dotada em essência de retórica.

É que as operaçóes que nos auxiliam a reconhecer a forma da paisagem por meio do "tropos" da linguagem figurativa já estão instaladas em nosso saber implícito: uma "bela paisagem" satisfaz, para nós, condiçôes que são comuns a nossa cultura. (CAUQUELIN, 2007, p. 116)

Deste modo, a representação da paisagem seria resultante de uma construção cultural, em que a compreensão de seu estado biofísico estaria entrelaçado ao entendimento de natureza que se tem nos distintos contextos socioculturais. Raymond Williams, em "Cultura e Materialismo", apresenta as diversas concepções de natureza enquanto construçóes históricas. Em um dos capítulos, chamado "Ideias sobre a Natureza", o autor expóe que o significado da palavra natureza (sem deixar de negar a existência da realidade biofísica do mundo natural) é uma gama dos diferentes usos do termo ao longo da história. Variando entre a significaçâo latina, natura, como uma espécie de lei imutável, constituinte da essência do mundo, e a crença de ser uma personificação divina e feminina (divine Mother), o autor afirma ser a ideia de natureza uma concepção humana e, para ir mais além, uma ideia do ser-humano social, pertencente aos distintos tipos de sociedade. Na sociedade moderna ocidental em específico, segundo Williams, a ideia de que a natureza seria um objeto a ser observado e experimentado, enquanto 
que uma "intervenção consciente para fins humanos" (WILLIAMS, 2011, p. 103), teria gerado um tipo de separação entre o humano e o universo natural. Resultante desse distanciamento, natureza e cultura tomaram posiçóes contrárias, sendo ainda hoje em grande parte entendidas como duas dimensóes separadas. A apreensão e a apreciação do ambiente natural, deste modo, é algo que perpassa diferentes contextos, podendo ser visualizadas por meio da arte.

Como um registro visual da natureza, a pintura de paisagem no ocidente não ganha autonomia como um gênero maior até o século XIX, uma vez que ela tem, todavia, um forte caráter simbólico e literário ao complementar, reforçar ou mesmo preencher uma dada cena que se desenrolaria no primeiro plano da pintura. Até então, não se pode considerar a paisagem como um gênero independente, pois a interpretação da natureza estava ainda atrelada à narrativa da cena principal, geralmente religiosa ou mitológica, sendo a paisagem ocupante do plano de fundo. Nos séculos XIV e XV europeus, os elementos da natureza eram pintados em detalhes em várias obras e iluminuras, já demonstrando a curiosidade e observação minuciosa do universo natural, especialmente na arte flamenga dos quatrocentos. Entretanto, a pintura desses artistas

(...) are full of wonderful passages of observation. But none of these painters considered that the recording of a true visual impression of nature was a sufficient end in itself. Landscape had to carry with it some literary association, or scenery be intensified to heighten some dramatic effect (CLARK, 1979, p. 54) ${ }^{1}$
$\mathrm{Na}$ Holanda seiscentista esse panorama muda quando a paisagem deixa de ter um sentido literário. Um dos gêneros que se tornou uma das maiores marcas da pintura holandesa do século XVII foi a pintura de paisagem, mesmo sendo ainda considerada um gênero secundário. Nessas telas se pode ver registros de diversas paisagens marinas, campesinas ou urbanas realizadas como um "espelho fiel" à realidade, em que são ausentes de alegorias e que oferecem aos espectadores a beleza de simplesmente observar o mundo como ele é - obviamente, questóes ligadas à moral e a conduta da sociedade protestante que eram estão presentes nas organizadas composiçóes e na simplicidade das formas. As paisagens naturais tomam um lugar de destaque na arte holandesa e vêm a ocupar o primeiro plano das telas como temática principal, perdendo a função de ser um mero plano de fundo. A beleza da natureza, que não deixa de ser uma criação divina aos olhos desses protestantes, torna-se então um motivo a ser descrito (ALPERS, 1999) através do amplo universo pictórico composto de cores, luzes e texturas.

Com o advento do romantismo em fins do século XVIII, o gênero paisagem foi de fato valorizado pelo meio artistico europeu. Os artistas levantaram questôes sobre a existência e também inauguram uma nova sensibilidade sobre a paisagem, em que "procuravam uma arte que deveria expressar a dimensáo espiritual da natureza” (HARGRAVES, 2014, p.16). E através da poética do pitoresco e do sentimento do sublime que a experiência do universo natural será melhor traduzido nas pinturas, desenhos e gravuras produzidas nesse período. Igualmente, os artistas românticos começaram a se interessar pelo processo de desenvolvimento da natureza também em seu aspecto físico - 
até porque este não estaria deslocado de um sentido místico ou filosófico - e esse interesse os levou a se aproximar mais da história natural, na intenção de se obter um maior entendimento dos diversos processos orgânicos, próprios ao universo natural (WOLF, 2007). Algo que colaborou com a valorização das pinturas de paisagem tanto por parte dos artistas, quanto por parte do público em geral. Entretanto, o espaço natural estava atrelado à impressão subjetiva do artista, sendo limitado à linguagem pictórica.

O universo biofísico está constantemente em modificação. Independentemente das ações humanas diretas sobre o ambiente natural, as mutaçóes serão sempre uma constante. No âmbito dos trabalhos da arte contemporânea que atuam no ambiente natural, a ideia de um tempo estático vinculado à noção de paisagem artística é reconsiderada, pois as obras tem a sua realização plena na realidade do mundo, por estarem inseridas em seu fluxo temporal ${ }^{2}$. O "aqui e o agora" da paisagem apreendido pela pintura passa a ceder nas instalaçóes ao tempo fluido e ativo espacialmente, entrelaçado às interferências artísticas no ambiente natural.

No caso de algumas instalações que datam dos anos 60 do século XX em diante, a contraposição entre natureza e cultura pode ser analisada como um entrelaçamento. Estas instalaçóes dialogam diretamente com o ambiente natural, tendo este como um elemento que se estende para além de seu mero estado biofísico, ao reconfigurar o espaço por meio das interaçóes instauradas.

II.

Somente por volta nos anos de 1960/70 que o meio biofísico se tornará de fato elemento compositivo de alguns trabalhos artísticos, como aqueles pertencentes à Land Art. Os trabalhos da Land Art foram feitos em desertos, em extensas paisagens, sob escalas quilométricas, onde a terra e seu complexo geológico eram a base para a elaboração da atividade artística. A natureza, desse modo, náo era simplesmente representada, e sim passa a compor em sua materialidade a obra artística. A Terra seria o campo de atuação e sua extensão ofereceria um material de proporçóes e possibilidades variadas em relaçáo aos suportes e espaços tradicionais da arte.

$\mathrm{O}$ que teria antes de tudo motivado os artistas dos anos 60 foi uma vontade de experimentar novos espaços que permitissem olhar a arte de outro modo. Também uma fascinaçáo pela terra ou pelos materiais naturais assim como a possibilidade de realizar in situ obras de grandes dimensões. (TIBERGHIEN, 2001, p.179)

Assim, a obra de arte ao invés de intencionar ser um objeto encerrado em sua própria espacialidade material, visa a ser e recriar o próprio espaço:

Para mim, uma peça de escultura dentro de uma sala é uma disrupção do espaço interno. É uma protuberância, uma adição desnecessária ao que poderia ser um espaço suficiente por si mesmo. (HEIZER, OPPENHEIM, SMITHSON, 2006, p. 275)

Deste modo, o lugar que aloja o objeto artístico não é algo independente do trabalho, ele mesmo é parte do trabalho, como um site especific. Como dito por Michael Heizer: "O trabalho não é posto em um lugar, ele é esse lugar" (idem), sendo o objeto a própria objetividade do espaço e a intervenção nesse mesmo 
espaço. Deste modo, diversos trabalhos da Land Art exploravam o espaço fora da galeria, muitas vezes como extensão dela, reinventando tanto uma outra temporalidade para a obra de arte como também repensando a forma desta.

Um exemplo relevante de obras que intervieram diretamente na terra é o já "clássico" Spiral Jetty (1970), de Robert Smithson. Sendo uma espiral feita em um lago em Utah (Great Salt Lake, Utah) se faz necessário caminhar ao longo dessa espiral para obtermos a real experiência da obra (Figura 1).

Ao longo do percurso, em direção ao que seria o centro da espiral, uma sensação de descentralização é sentida pelo caminhante que se desloca na vastidáo do lago salgado e de águas vermelhas coloridas por algas. $\mathrm{Ou}$ seja, através do deslocamento do corpo o observador tem acesso à multiplicidade de significaçôes propostas pela obra, em que o inesperado e a indeterminação são incorporados no trabalho de arte. Do mesmo modo, a experiência temporal de Spiral Jetty dissolve a idéia de um tempo sucessivo. A temporalidade aqui é composta da duração do observador enquanto experimentando e participando da temporalidade geológica daquele vasto espaço. Isto é, o observador que caminha ao longo da espiral é inserido na temporalidade das perpétuas transformaçôes naturais, em seu tempo milenar, sendo o presente da experiência corporal absorvido pelo passado da memória natural, a qual se mantém desdobrando-se no eterno devir da atualidade. Uma obra que requer a consciência do tempo e de sua grandiosidade através da experimentação espacial.

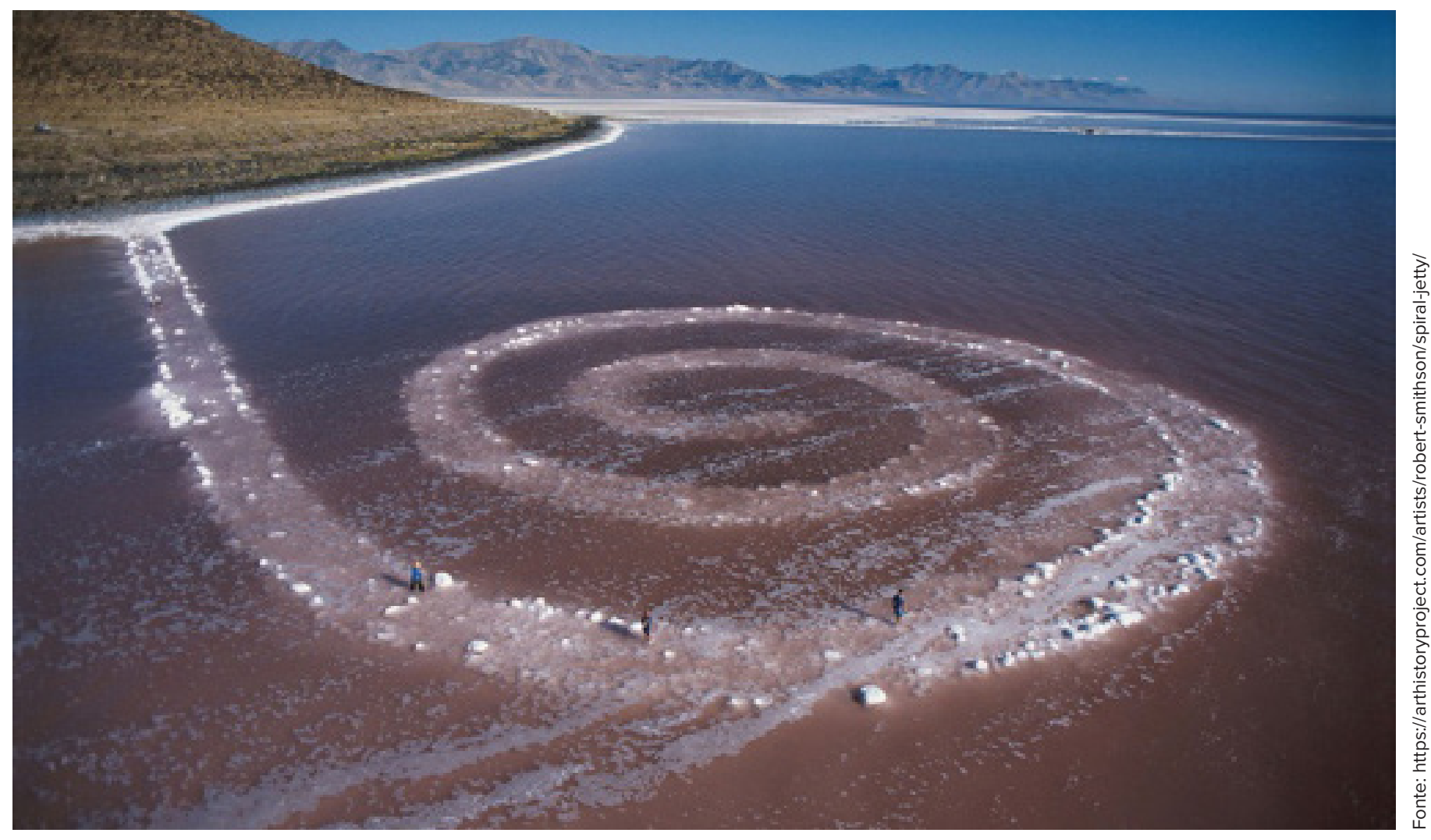

Figura 1: Spiral Jetty, Robert Smithson, 1970. 
Em Pelo espaço, a geógrafa Doreen Massey fala do lugar como eventualidade ao afirmar que tudo está sempre em movimento, tanto as coisas relativas à Terra quanto o próprio Universo. Assim como as marés do oceano, a terra firme estaria sofrendo diariamente um processo de subida e descida, ao mesmo tempo em que as rochas estariam também a se mover. Deste modo, a noção de um ponto estável, ou de uma fixidez do lugar corresponderia a um processo, a uma tarefa inacabada: "Lugares não como pontos ou áreas em mapas, mas como integraçóes de espaço-tempo, como eventualidades espaço-temporais" (MASSEY, 2008, p 191).

Uma noçáo de lugar que nos remete à obra o Grande Budha (realizada em 2000, sendo o projeto de 1985), de Nelson Felix, a qual hoje só seria encontrada a partir do uso de um GPS 3 . Nesse trabalho, garras em ferro foram colocadas em volta de uma árvore em uma floresta no Acre, contando que durante o processo de seu crescimento, que leva cerca de 700 anos, tais garras seriam absorvidas e integradas ao tronco da árvore, uma vez que o interior ("um centro entrópico") do tronco tende a se expandir para fora (Figura 2).

Feita essa intervenção no meio de uma floresta, a própria árvore cercada tende a desaparecer entre os elementos do ambiente, ao mesmo tempo em que essas garras foram colocadas também para sumir em meio ao processo de crescimento da árvore. Deste modo, este lugar ocupado pela obra se torna incerto, quase uma abstração, tanto em relação à intervenção feita em uma árvore entre outras centenas quanto à colocação de garras em ferro intencionadas a desaparecer no devir próprio ao processo natural.
O trabalho se utiliza de uma árvore e seu tempo, mas seu principal interesse é a floresta. Uma árvore, neste contexto, é um igual entre iguais; a floresta é uma imensidão cheia, construída por semelhantes. Onde tudo é o mesmo, cria-se uma unidade sem referência, perde-se a escala, produzindo um espaço de ordem desnorteada. (...) Duas poéticas direcionam esta escultura: primeiro, a impossibilidade de convivência com o trabalho na dimensão de tempo, de vê-lo em sua completude (setecentos, oitocentos anos de formação); em segundo, a consciência da per$\mathrm{da}$, que remete esse espaço sem referência. (Nelson Félix, http://nelsonfelix.com.br/ obras/projetos/cruz-na-america/)

Um tipo de trabalho, então, que se deixa ficar à mercê do meio, sendo ao fim parte deste mesmo espaço e de sua temporalidade. Uma obra que é em si o próprio processo, onde dispositivo cultural (garras) e natureza (floresta) se tornam uma coisa única.

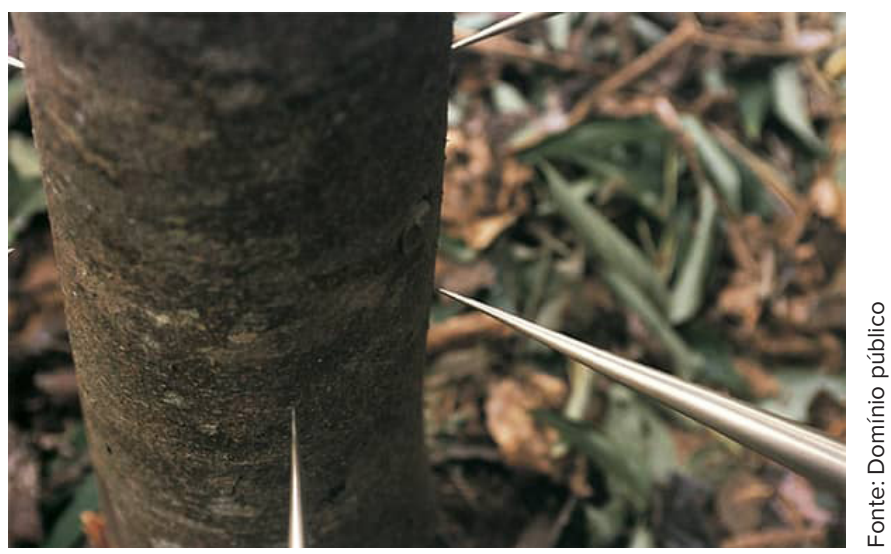

Figura 2. Grande Budha, Nelson Felix, 2000. 
Ocorrentes os trabalhos de arte em ambiente incerto, ou seja, variáveis em diversos sentidos, é plausível repensarmos a noção de experiência do espaço artístico. O espectador ao invés de lidar com a apreensão do "momento" estático e definido que pode ser gerado pela obra artística, experimenta as interconexóes ocorrentes no devir próprio das coisas no mundo. Desta maneira, o corpo, a memória e a imaginação se tornam parte da própria obra, que então exige a participação do "espectador".

A obra Passarelas, de Eduardo Coimbra, feita em 2008 para o Museu do Açude, no Rio de Janeiro, é interessante para pensarmos o que seria a experiência do ambiente natural/cultural. Nesse trabalho, 32 metros de passarelas de madeira e aço foram instaladas, permanentemente, no alto dos troncos das árvores da área externa do museu (Figura 3 e 4).

Durante a nossa experiência da obra/paisagem convivemos com vários pontos de vistas do lugar por estarmos imersos nele, dentro do espaço, mesmo que da floresta. No momento em que estamos andando pelas passarelas, adentramos por entre as árvores e por vezes alcançamos a sua altura, experimentando a paisagem de dentro dela, de uma maneira sensorial, que se estende para além do visual (o tronco, as folhas, o musgo, o vento, o cheiro, o calor e o frio). Deste modo, nossa relação com o ambiente natural se torna, por um momento, menos "distanciada", uma vez que cultura e natureza se mesclam, sendo nossa compreensão em grande parte sensorial: "O pensamento da paisagem na obra de Eduardo Coimbra, como ele próprio define, 'surge da dualidade entre a paisagem como imagem e a paisagem como matéria." ${ }^{4}$. Aqui nosso contato é físico, em que nossos sentidos, tato, olfato, audição, fazem parte dessa experiência artístico-espacial. A experiência sonora do barulho provo-

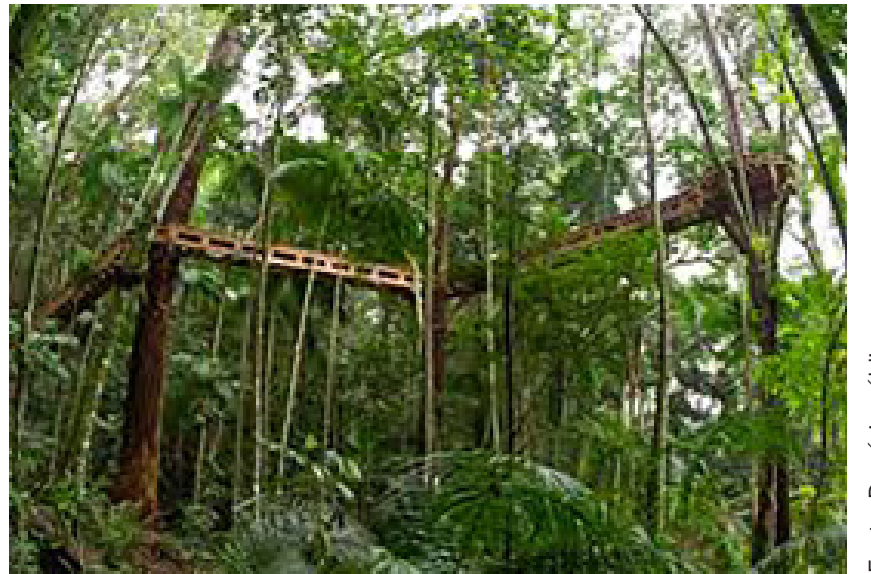

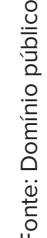

Figura 3. Passarelas, Eduardo Coimbra, 2008.

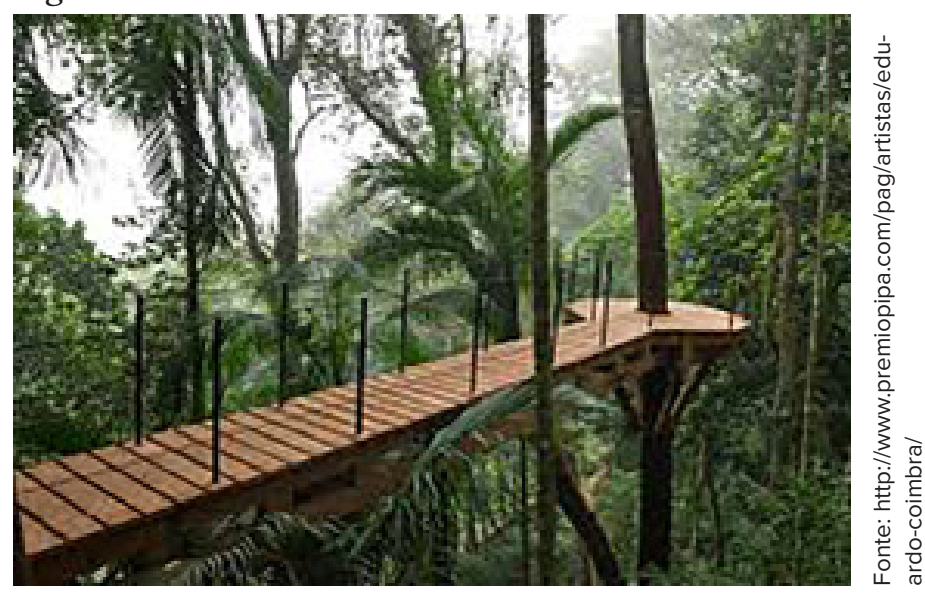

Figura 4. Detalhe do mirador.

cado pelo vento sobre as folhas das árvores também se torna diferente, uma vez que estamos entre elas, adentrados em seu ambiente e nos percebemos a centímetros de suas copas. E o mais curioso nessa exploração das diversas possibilidades dos pontos de vista é que em partes das passarelas nos deparamos com "outras paisagens", como morros ao fundo observados das partes mais altas e dos mirantes. Mas essa visualização de um ponto distante ocorre simultaneamente ao nosso estar dentro da paisagem, criando uma certa tensão, um tanto irônica, do que poderíamos chamar realmente de paisagem natural. Isso porque, segundo o curador das instalaçôes permanentes do museu, Marcio Doctors, haveria por par- 
te do artista um desejo de preservar a experiência visual, entendendo como um aprofundamento da externalidade: "O ato de ver como imersão no mundo físico; como mergulho na exterioridade." 5

O fato de caminharmos sobre as passarelas requer o deslocamento de nossos corpos, originando várias possibilidades do olhar naquele espaço. Temos, assim, a instalaçâo como uma "paisagem móvel" que entra em acordo com o processo mutável da própria natureza (chuva, sol, frio) e que compartilha ao fim um espaço-tempo relativo e instável, fazendo da instalação permanente sempre uma experiência indeterminada. Se vivencia, desse modo, uma paisagem natural/cultural.

Outro trabalho interessante nesse contexto é o Green River (1998), de Olafur Eliasson. Em 1998, o artista jogou um produto chamado uranio fluorescente, utilizado para analisar as correntes marítimas e fluviais, sobre o rio da parte norte de Fjallabak, na Islândia e em anos posteriores em mais cinco cidades. Tal produto pigmenta a água de verde a deixando com um tom artificial, mudando automaticamente a aparência do rio e de seu entorno (Figura 5 e 6).

Segundo o artista $^{6}$, essa coloração artificial da água acaba por ressaltar a presença do rio, que passa despercebido no cotidiano das pessoas, deixando de ser invisível para tornar-se visível naquele local. Ao mesmo tempo é criada uma espécie de hiper-realismo provocado pela cor verde sobre aquilo que seria um elemento natural. No caso da Islândia, o evento ocorreu em uma paisagem não urbana ${ }^{7}$ (os outros aconteceram dentro de cidades). $\mathrm{O}$ rio passava por uma regiáo vulcânica, caracterizada por uma paisagem cinza e rochosa, em que a cor verde na água causava uma aparência estranha ao lugar. E com isso a paisagem toda

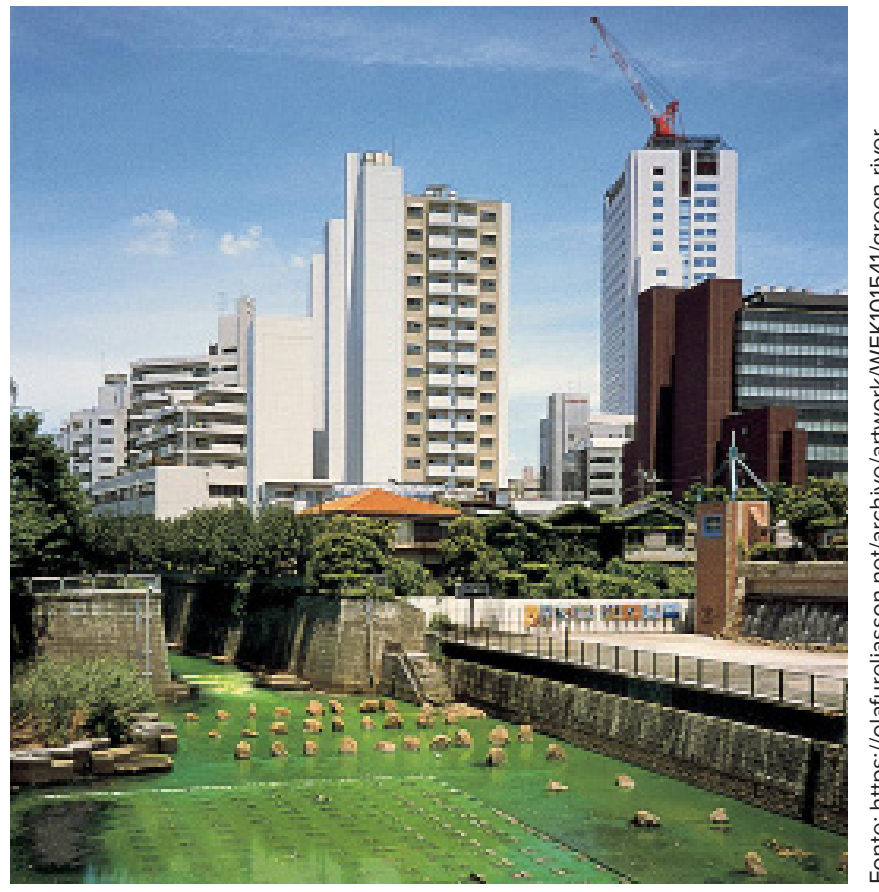

Figura 5. Green River (Tokyo, 2001), Olafur Eliasson.

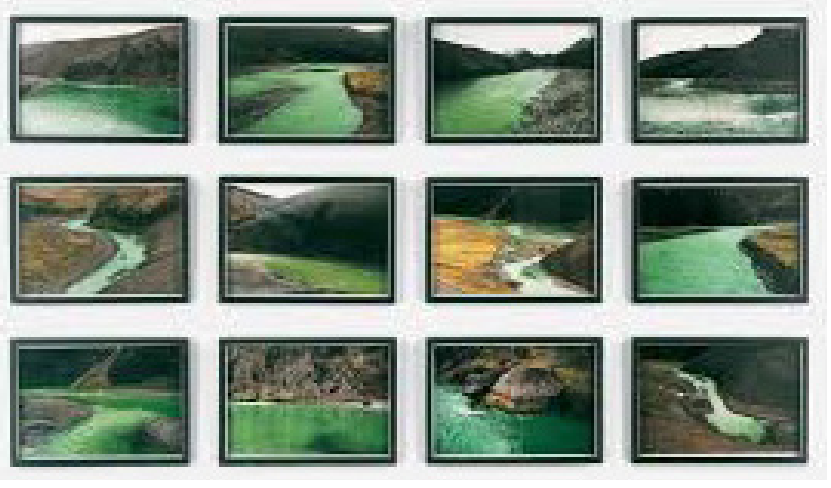

Figura 6. Green River, The Northern Fjallabak Route, Islandia, 1998.

se modificou, não sendo mais aquela costumeira aos habitantes da região. Uma mudança radical que também visa a chamar a atenção para a nossa convivência com os elementos da natureza e para as suas alteraçóes, sejam feitas pelos humanos sejam pelo próprio processo natural. Da mesma forma, um rio é necessariamente um processo, um entre, um caminho entre um certo lugar (nascente) e outro (mar) — lugares estes também 


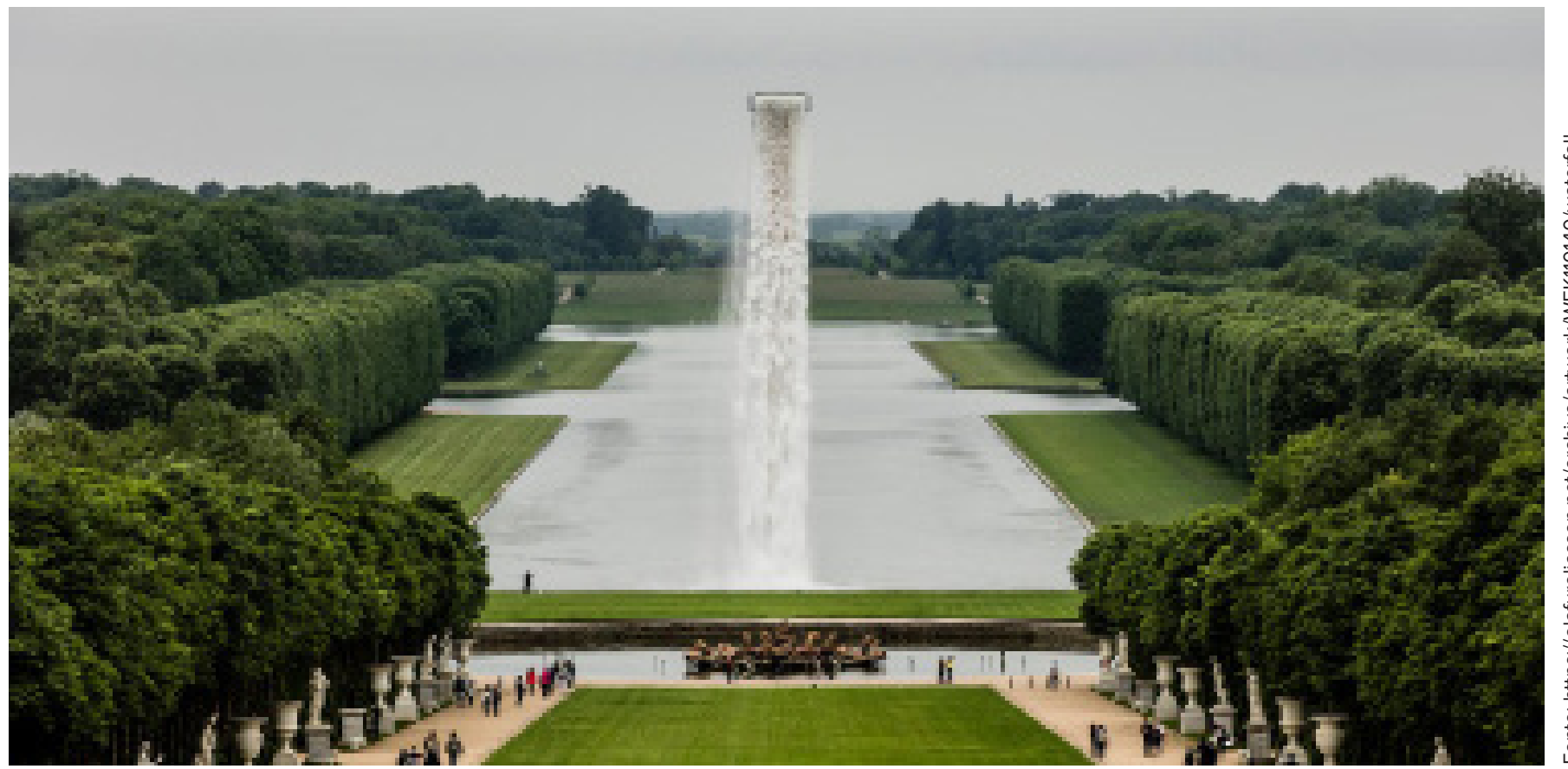

Figura 7. Waterfall, Olafur Eliasson, 2016.

imprecisos ao longo dos processos que se desenrolam na amplitude geográfica, se seguirmos a concepção de Massey (ou mesmo se pensarmos nas intersecçôes das coisas do mundo (MERLEAU-PONTY, 2007). O tempo age sobre o espaço que atua sobre o tempo e em nós consequentemente. E Olafur quer que percebamos o que está a nossa volta para que voltemos a olhar e a repensar o espaço, seja ele urbano ou natural, mas que se encontra em um continuo processo de transformação.

Ao ressaltar a presença dos rios, de suas correntezas e de seu movimento constante, algo de virtual é deflagrado, uma vez que a tonalidade fluorescente na água é extremamente artificial à paisagem em questão. Uma espécie de hibridismo entre o natural e o artificial torna-se visual, levantando questôes sobre como veríamos de fato os fenômenos e elementos naturais e o que seria a nossa convivência com a paisagem. A partir da tensão então deflagrada entre natureza e cultura,
Olafur Eliasson vai provocar a nossa percepção sobre o artificial e o natural, não buscando uma resposta para o problema, mas fazendo-nos refletir sobre como vemos e convivemos com o nosso entorno.

Outro trabalho do mesmo artista que merece ser mencionado é a série Waterfalls, em especial a instalação feita em 2016 nos jardins do Palácio de Versalhes, França (Figura 7).

Essa fantástica instalação cria um efeito virtual na paisagem secular dos jardins de Versalhes, rompendo com a sua ordem tradicional e provocando experiências pessoais nos visitantes do Palácio.

The visible infrastructure of the waterfall calls attention to the constructed nature of both the work itself and the surrounding gardens, while the tumbling water highlights the presence of larger natural 
forces that play upon this contrived environment: the strength and direction of the wind, the conditions of the light at a particular moment. ${ }^{8}$ (https://olafureliasson.et/archive/artworkWEK110140/ waterfall)

Nesse texto do site oficial de Olafur Eliasson está claro que o ambiente em si mesmo, juntamente aos efeitos criados pela presença da água que jorra como uma cachoeira, são parte componentes da instalação, de forma que os elementos e efeitos naturais (vento, luz, água, etc...) são levados em conta enquanto tal. Uma mescla entre o que compreendemos como natureza e cultura é acionada, fazendo-nos repensar a nossa própria compreensão de realidade, e mesmo de verdade. Pois, é possível uma cascata "solta" na água, independente de uma formação rochosa? Longe de um espaço "verde" e natural? Essa realidade artificial que o artista cria desorienta a nossa percepção sobre a nossa concepção sobre o espaço natureza e o espaço cultura, de maneira que provoca a nossa ideia de permanência em um lugar (natural ou cultural) específico. Ou seja, natureza e cultura estáo intimamente entrelaçadas na nossa atual compreensão daquilo que é natural, assim como o espaço que pensamos ser unicamente cultural (por exemplo, as cidades) está estruturado pela natureza (terra, rios, ar, atmosfera, componentes químicos, etc...).

Assim como na instalação de Eduardo Coimbra, imagem e realidade entram em tensão ao se mesclarem na experiência do site specific. Como vimos, Coimbra trabalha a experiência da imagem na espacialidade real, não ressaltando as diferenças entre o ver e o tocar, mas as confundindo como ação conjunta no espaço real ${ }^{9}$. Do mesmo modo, Eliasson acaba por produzir uma imagem virtual no campo da realidade, na intençáo de fazer submergir o real às nossas vistas. Porém, em ambos os trabalhos nos deparamos com algo de fictício deflagrado na e pela paisagem. Trabalhar a paisagem enquanto realidade tangível acaba por provocar uma tensão entre o fantástico e a realidade devido à imagem que se cria a partir da intervenção artística. Vemos que ao mesmo tempo em que a arte se aproxima do real, o qual é ressaltado pela interação, uma tensão é criada pela "imagem artística" — que não deixa de ser também real, tangível - que surge daí: como passarelas suspensas no alto de árvores ou como um rio verde fluorescente. A realidade é, assim, ressaltada em sua objetividade através de uma espécie de absurdo criado pelo artista.

\section{III.}

Deste modo, as instalaçóes discutidas nesse artigo nos fazem questionar sobre a significação do lugar que experimentamos. Cada qual com sua forma em particular, essas obras vão pensar o espaço relacionado aos elementos da natureza e a sua experimentaçáo pelo público através da arte, fazendo esse mesmo público refletir sobre a sua própria compreensão de "ambiente natural".

Essas instalaçóes são, assim, como desdobramentos na paisagem natural/cultural. Por isso, se faz necessário considerarmos a paisagem enquanto elemento ativo do trabalho, entâo como um entrelaçamento entre arte, cultura e natureza. Ao ter essas instalaçóes a sua realização plena na temporalidade espacial do mundo (em um lugar específico externo), faz com que a experiência do espectador também se confunda com o devir constante que se desenrola nas paisagens artísticas. E devido à instabilidade dos dias e do clima — um dia pode fazer sol, outro chuva; a luz da manhã é distinta 
da luz da tarde - a paisagem reconfigurada pelo site specific será sempre um lugar instável e inapreensível para além de um presente imediato e vivido pelo espectador; este que se torna participante da obra ao também fazer parte da paisagem reconfigurada.

\section{Notas de fim:}

1. (...) estão cheias de maravilhosas passagens de observação. Mas nenhum desses pintores considerou que o registro visual de uma verdadeira impressão da natureza era um fim suficiente em si mesmo. A paisagem tinha que ter alguma associação literária ou o cenário era intensificado para aumentar algum efeito dramático. [tradução livre]

2. Me pareceu nesse artigo desnecessário entrar na discussão da arte no movimento Dadá, pois aqui o tema principal é a interação entre arte e paisagem "natural", e não necessariamente um apanhado histórico relacionado as questóes que envolvem simplesmente arte e externalidade.

3. O deslocamento numa dimensão global, guiado por coordenadas, é algo que permeia a obra de Felix. Porém, trazendo consigo um híbrido entre espaço real e espaço mental, uma vez que coordenadas são essencialmente construçóes racionais de um lugar específico no espaço da Terra ou do Universo.

4.http://portal.iphan.gov.br/uploads/ckfinder/arquivos/ passarela.pdf

5. O texto escrito por Doctors foi publicado no folder do Projeto Arte e Patrimônio, Paço Imperial/IPHAN,Rio de Janeiro, 2008.

6. OBRIST, Hans U. Arte Agora!: em 5 entrevistas. São Paulo: Alameda, 2006.

7. "Fiz também na Islândia, no campo: queria ver em um ambiente artificial e em um outro, digamos, natural, pesquisando o que um rio provoca em uma cidade ou em uma paisagem natural.” (idem, p.50)
8. A infra-estrutura visível da cachoeira chama a atenção para a natureza construída tanto do trabalho em si quanto dos jardins circundantes, enquanto a água em movimento destaca a presença de forças naturais maiores que atuam nesse ambiente criado: a força e a direção do vento, as condiçóes da luz em um momento particular. [tradução livre]

9. Como no Quiasma de Merleau-Ponty, em O Visível e o Invisivel, em sua noção de visão tangível. Nesse texto ele diz que aquele que vê só vê porque também é visto, assim como aquele que toca só toca porque é tocado, mas que só se vê porque o ver apalpa o que é visto. Ou seja, o olhar é tangível, não concluído na retina.

\section{Referências Bibliográficas}

ALPERS, Svetlana. A arte de descrever: a arte holandesa no século XVII. São Paulo, EDUSP, 1999.

CLARK, Kenneth. Landscape into Art. London: John Murray Ed, 1979.

CAUQUELIN, Anne. A invenção da paisagem. São Paulo: Martins Fontes, 2007.

HARGRAVES, Matthew e SLOAN, Rachel. A dialogue with nature: romantic landscape from Britain and Germany. London: The Courtauld Gallery, 2014.

HEIZER, OPPENHEIM, SMITHSON. Discussöes com Heizer, Oppenheim, Smithson. In: Escrito de artistas: anos 60/70. Rio de Janeiro: Jorge Zahar, 2006.

MASSEY, Doreen. Pelo Espaço. Rio de Janeiro: Bertrand Brasil, 2008.

MERLEAU-PONTY, M. O visivel e o invisivel. São Paulo: Perspectiva, 2007.

O olho e o espirito. In: Os Pensadores. São Paulo: Abril Cultural, 1975

OBRIST, Hans U. Arte Agora!: em 5 entrevistas. São Paulo: Alameda, 2006. 
TIBERGHIEN, Gilles. Nature, Art, Paysage. Actes Sud/ École Nationale Supérieure Du Paysage, 2001.

WILLIAMS, R. Ideias sobre a Natureza. In: Cultura e Materialismo. São Paulo: Ed. Unesp, 2011.

WOLF, Norbert. Romanticism. London: Taschen, 2007. 